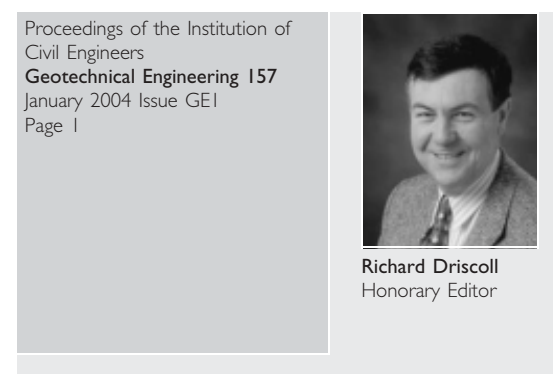

\title{
Editorial
}

\section{Richard Driscoll}

Welcome to the first issue of Geotechnical Engineering in 2004.

2003 was a mixed year for the journal. Early on, we were short of enough papers to ensure a sufficiently consistent quantity and quality of publication. As the supply of material showed little sign of building to a comfortable level, the Advisory Panel decided to instigate a one-off, Special Issue by inviting contributions on 'The Geotechnics of Transport Infrastructure', to be published in October 2004. I am pleased to report that this initiative has every sign of yielding the desired result of creating a larger buffer of papers progressing through the publications process: to date, we have 27 promising synopses. If only half of them progress to publication, we'll have exceeded our objective by a comfortable margin.

At the end of 2003 the Editorial Panel said 'farewell and thanks' to four hard-working members: Rachel Nichols, Myles Andrews, Steve Rees and Steve Smith. I am very pleased to welcome their replacements: Dominic Holt of Arup Geotechnics, David Jones of Bechtel, David French of Atkins and Matthew Raybould of SWK. Nick Wharmby has also left the panel on his departure to New Zealand; Nick has kindly volunteered to become an Overseas Panel Member for the journal in his new homeland.

A number of our Overseas Panel members have finished their term of service and I am pleased to welcome two new members: Doug Stewart, in Australia and Guo Hui Lei in the People's Republic of China.
I am also pleased to report that three of our papers won Institution of Civil Engineers prizes in 2003

- Pilot in situ auger mixing treatment of a contaminated site. Part 4-Performance at five years by Al-Tabbaa and Boes (July 2002) won the Reed and Mallik Medal

- Groundwater control for construction in the Lambeth Group by Preene and Roberts (October 2002) won a Halcrow Prize

- The Observational Method-learning from projects by Powderham (January 2002) also won a Halcrow Prize.

Apart from the inexorable search for new, high quality papers, a key aim for 2004 is to increase the amount of Discussion. Looking back 20-plus years, a notable change has been the decline in written Discussion in the ICE Proceedings. Three questions: does this reflect a decline in significance in the content of papers; or are they less controversial and provocative; or are readers simply far too busy to respond to what they read? Whatever the cause, we hope that our journal will prompt you to write to us.

I wish you all a productive 2004.

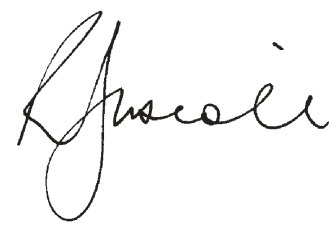

